\title{
Effect of feeding whole linseed as a source of polyunsaturated fatty acids on performance and egg characteristics of laying hens kept at high ambient temperature
}

\section{-Author(s)}

Ahmad S1 (Corresponding Author)* Ahsan-ul-Haq²

Yousaf $\mathrm{M}^{2}$

Kamran Z1

Ata-ur-Rehman ${ }^{3}$

Sohail MU'

Shahid-ur-Rahman²

University College of Veterinary and Animal Sciences, The Islamia University

Department of Poultry Science, University of Agriculture, Faisalabad 38040, Pakistan

3 Research Support Section, Pakistan Science Foundation, Islamabad 44000, Pakistan

DVM - Granjas Kakimoto

5 Ph. D. student at the Department of Animal Science /FMVZ/UNESP/Botucatu

* Post-doctorate grant given by Fundação de Amparo a Pesquisa do Estado de São Paulo Process n. 2007/06707-8

\section{Mail Adress}

*Corresponding author e-mail address University College of Veterinary and Animal Sciences, The Islamia University of Bahawalpur 63100, Pakistan.

Phone No.: +92629239180

E.mail: drshakeel@mail.com

\section{- Keywords}

Linseed, n-3 PUFA, laying hens, hot climate, performance.

\section{ABSTRACT}

The present study was conducted to evaluate the effects of feeding whole linseed on the laying performance and egg characteristics in laying hens kept at high ambient environmental temperatures (average $34^{\circ} \mathrm{C}$; the diurnal temperature range $26^{\circ} \mathrm{C}$ to $41^{\circ} \mathrm{C}$ ). Two hundred and forty 38-wk-old white Leghorn laying hens were fed diets containing 0, 5, 10 or $15 \%$ whole linseed (as a source of $n-3$ polyunsaturated fatty acids) for a period of 12 weeks. Egg production was recorded daily, while feed intake and egg characteristics were monitored on weekly basis. The results of the study demonstrated that egg production and feed intake decreased, while feed conversion ratio (FCR) per dozen of eggs increased $(p \leq 0.05)$ with increasing dietary linseed levels. Egg weight, yolk weight, albumen height, eggshell weight, and eggshell thickness were not influenced ( $p>0.05$ ) by linseed levels in the diets offered to the laying hens. The results of the present trial suggest that feeding linseed to the laying hens in hot climates has no detrimental effects on egg characteristics, but has suppressive effects on egg production, feed intake and feed efficiency of laying hens.

\section{INTRODUCTION}

Linseed is a very rich source of $n-3$ polyunsaturated fatty acids (PUFA) among many vegetable sources (Botsoglou et al., 1998). It is well documented that n-3 PUFA bring potential benefits for human health. This is why many researchers have focused on linseed inclusion in the diets of layers to enhance egg n-3 PUFA content. However, laying performance has not been much emphasized in such studies. Contradictory results on the performance of layers fed linseed as a source of n-3 PUFA have been reported. Some studies indicate that there are no differences in egg production, egg weight, eggshell weight, eggshell thickness and albumen height when layers are fed 0 or $10 \%$ linseed (Bean \& Leeson, 2003). Aymond \& VanElswyk (1995) observed a decrease in egg production in layers fed 15\% linseed; however, other authors reported an increase in egg production when hens were fed 5 , 10 and 20\% linseed (Scheideler \& Froning, 1996; Beynen, 2004). Bean \& Leeson (2003) and Beynen (2004) reported a decrease in feed intake, whereas Caston et al. (1994) and Novak \& Scheideler (2001) found a significant increase in feed intake when layers were fed diets containing linseed. In a trial, diets containing 20\% linseed reduced egg weight (Beynen, 2004). Similarly, Sosin et al. (2006) also indicated reduced egg weight when layers were fed linseed. Bean \& Leeson (2003) found yolk weight reduction in layers consuming linseed, whereas Sosin et al. (2006) reported that feeding linseed to layers had no effect on the yolk weight. Considering these contradictory results, the effects of linseed feeding on layer performance needs to be further evaluated. 
Most trials on linseed feeding of layers conducted in the past were carried out in temperate climates, and there is little information available on the performance layers reared at high ambient environmental temperatures in response to diets containing linseed as a source of n-3 PUFA. Thus, the present study was designed to investigate the effects of feeding linseed on the performance and egg characteristics of layers kept at high cyclic ambient temperature.

\section{MATERIALS AND METHODS}

\section{Birds, Housing, Experimental Design and Data Collection}

Two hundred and forty 38-wk-old single-comb white Leghorn laying hens were randomly distributed into 24 experimental units, designated as replicates. These replicates were randomly allotted, according to a completely randomized experimental design, to treatment groups A (control), B, C, and D, each comprising 60 birds, which were offered experimental diets for a period of 12 weeks. Hens were housed in cages (two birds/cage) providing $0.093 \mathrm{~m}^{2}$ floor space area per bird, and maintained at high environmental temperature (diurnal temperature ranged between 26 and $41^{\circ} \mathrm{C}$, with an average of $34^{\circ} \mathrm{C}$ ) throughout the study. Treatment groups A, B, C and D were fed diets containing $0,5,10$ or $15 \%$ whole linseed, respectively. All diets were isocaloric and isoproteic (Table-1) and were formulated according to the recommendations of National Research Council (1994). Hens had ad libitum access to feed and water and a lighting program of 16L:8D was applied to all treatment groups throughout

Table 1 - Ingredients and nutrient composition of layer diets

\begin{tabular}{|c|c|c|c|c|c|c|c|c|c|}
\hline $\operatorname{Diet} C^{3}$ & Diet $D^{4}$ & & & & & & & & \\
\hline Ingredients & & & & & $\%$ & & & & \\
\hline Corn & & & 65.00 & & 51.18 & & 47.90 & & 44.00 \\
\hline Rice broken & & 4.40 & & 11.30 & & 11.35 & & 10.00 & \\
\hline Soybean meal & & 18.50 & & 18.60 & & 18.8 & & 20.00 & \\
\hline Corn gluten & & 4.00 & & 4.40 & & 2.40 & & 1.30 & \\
\hline Linseed & & 0.00 & & 5.00 & & 10.0 & & 15.0 & \\
\hline Limestone & & 6.92 & & 7.30 & & 7.38 & & 7.50 & \\
\hline DCP & & & 0.72 & & 1.66 & & 1.64 & & 1.62 \\
\hline L-lysine & & 0.08 & & 0.15 & & 0.12 & & 0.14 & \\
\hline Dl-methyonine & 0.03 & & 0.06 & & 0.06 & & 0.09 & & \\
\hline Vit./min premix 1 & 0.35 & & 0.35 & & 0.35 & & 0.35 & & \\
\hline Total & & & 100 & & 100 & & 100 & & 100 \\
\hline \multicolumn{10}{|c|}{ Nutrient Composition } \\
\hline $\mathrm{CP}(\%)$ & & & 17.00 & & 17.00 & & 17.00 & & 17.00 \\
\hline ME (Kcal/kg) & & 2900 & & 2900 & & 2900 & & 2900 & \\
\hline $\mathrm{EE}(\%)$ & & & 3.22 & & 3.40 & & 3.48 & & 3.55 \\
\hline CF $(\%)$ & & & 3.88 & & 3.70 & & 3.80 & & 4.01 \\
\hline $\mathrm{Ca}(\%)$ & & & 3.24 & & 3.27 & & 3.28 & & 3.26 \\
\hline Av.P (\%) & & 0.41 & & 0.42 & & 0.42 & & 0.41 & \\
\hline Lysine (\%) & & 0.90 & & 0.91 & & 0.91 & & 0.90 & \\
\hline Methionine (\%) & 0.38 & & 0.37 & & 0.36 & & 0.38 & & \\
\hline Threonine (\%) & & 0.64 & & 0.65 & & 0.64 & & 0.63 & \\
\hline
\end{tabular}

1 Provided per kilogram of diet: Vitamin A (Retinyl Palmitate), 3,000 IU ; Cholecalciferol, 1,250 IU; Vitamin E (dl-alpha-tocopheryl acetate), 12 IU;

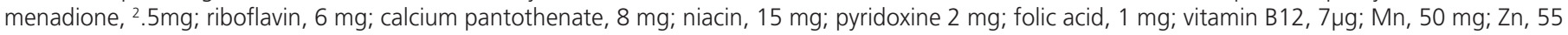
$\mathrm{mg}$; Fe $40 \mathrm{mg}$; Cu, 4 mg; l, 2 mg; Co, 0.3 mg; ethoxiquin, $150 \mathrm{mg}$.

'Diet A (control diet) with $0 \%$ linseed

${ }^{2}$ Diet B with $5 \%$ linseed

${ }^{3}$ Diet $C$ with $10 \%$ linseed

${ }^{4}$ Diet D with $15 \%$ linseed 
Table 2 - Effect of feeding whole linseed on laying performance of hens kept at high ambient temperature for a period of 12 weeks.

\begin{tabular}{|c|c|c|c|}
\hline & Hen-day Egg Production & Feed intake & Feed Conversion Ratio \\
\hline Item & $(\%)$ & (g/day) & ( $\mathrm{kg}$ feed/dozen of eggs) \\
\hline \multicolumn{4}{|l|}{ Diets $^{1}$} \\
\hline A & $69.36^{a}$ & $98.00^{\mathrm{a}}$ & $1.70^{\mathrm{b}}$ \\
\hline B & $66.67^{\mathrm{ab}}$ & $96.67^{\mathrm{ab}}$ & $1.76^{\mathrm{ab}}$ \\
\hline C & $63.93^{\mathrm{ab}}$ & $96.33^{\mathrm{ab}}$ & $1.81^{\mathrm{ab}}$ \\
\hline D & $60.86^{b}$ & $95.34^{a}$ & $1.88^{b}$ \\
\hline SEM & 2.029 & 0.516 & 0.045 \\
\hline ANOVA & ----------------------- & -------- Probability --------- & ---------------- \\
\hline Diet & 0.044 & 0.014 & 0.047 \\
\hline Linear & 0.004 & 0.001 & 0.006 \\
\hline Quadratic & 0.925 & 0.747 & \\
\hline
\end{tabular}

a-b Means within a column with different superscripts differ significantly $(p \leq 0.05)$

${ }^{1}$ Diets $A, B, C$ and $D$ have linseed level $0,5,10$, and $15 \%$, respectively.

the study. The experiment was conducted according to the ethical and welfare standards for experimental use of animals set by the Directorate of Research and Advance Studies, University of Agriculture, Faisalabad, Pakistan.

Egg production was daily recorded per replicate, whereas feed intake and feed conversion ratio/dozen eggs were weekly recorded. Two eggs per replicate were collected at random at weekly intervals to determine egg weight, yolk weight, albumen height, eggshell thickness and eggshell weight.

\section{Statistical Analyses}

Results were submitted to one-way analysis of variance (ANOVA) using GLM procedure, and Tukey's honestly significant difference test was used to compare the means (Minitab 13.1, Minitab Inc., State College, PA). Linear and quadratic regression analyses were also done to estimate hens' response to various linseed levels (Steel et al., 1997).

\section{RESULTS}

The effects of feeding whole linseed on layer performance are shown in Table 2. Egg production and feed intake linearly decreased ( $p \leq 0.05$ ) as dietary linseed level increased. Feed conversion ratio per dozen of eggs also linearly increased ( $p \leq 0.05$ ) with dietary linseed levels. All the other evaluated egg quality parameters, including egg weight, yolk weight, albumen height, eggshell weight and eggshell thickness were unaffected ( $p>0.05$ ) by feeding linseed to the laying hens (Table-3).

\section{DISCUSSION}

Most of the previous trials conducted on linseed feeding mainly focused on the dietary enrichment of eggs with n-3 PUFA, and did not consider performance or egg quality parameters, which are critical for commercial layer enterprises. In the present study, the performance and egg quality of the hens receiving linseed in the diet was emphasized. Furthermore, most of the researchers performed linseed feeding trials in temperate or controlled climates. There is no study available on the effects of linseed feeding of layers maintained at high temperatures in sub-tropical and tropical climates. As most layers are reared in open-sided houses in our sub-continent, the present study was carried out with laying hens kept at high cyclic ambient temperature to find out the effect of linseed feeding on the their performance and egg characteristics.

Egg production and feed intake linearly decreased (Figure 1 and Figure 2) as the dietary level of linseed increased. It has been suggested that the anti-nutritional factors contained in the linseed may impair the digestion and absorption of energy-yielding nutrients (GonzalezEsquerra \& Leeson, 2000; Rodriguez et al., 2001). Ortiz 
Table 3 - Effect of feeding linseed on egg characteristics of laying hens kept at high ambient temperature for a period of 12 weeks.

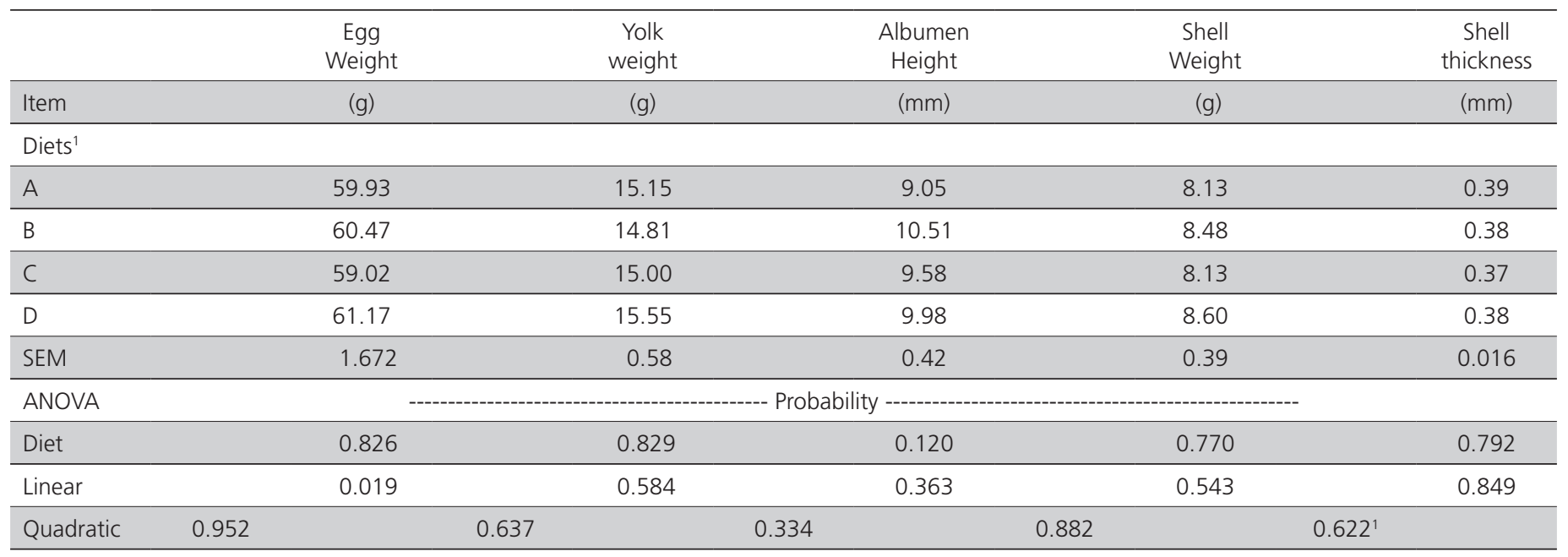

Diets $A, B, C$ and $D$ have linseed level $0,5,10$, and $15 \%$, respectively.

et al. (2001) concluded that deleterious compounds in the linseed interact with other dietary nutrients in linseed-based diets, impairing digestion and absorption and ultimately decreasing dietary $\mathrm{AME}_{\mathrm{n}}$. Therefore, anti-nutritional factors in linseed may have been the cause of the decrease in egg production in the present trial. It was noted during the study that egg production and feed intake of birds in all treatment groups tended to be low, and did not reach their genetic potential also due to the hot weather. The inclusion of linseed in the feed produced some off smell, which may have reduced feed intake as dietary linseed level increased. The reduced feed intake, combined with the poor nutrient availability in the diets containing linseed, may explain the poor FCR per dozen eggs observed. The results of the present trial are in agreement with those of Aymond \& Van Elswyk (2005), who reported a

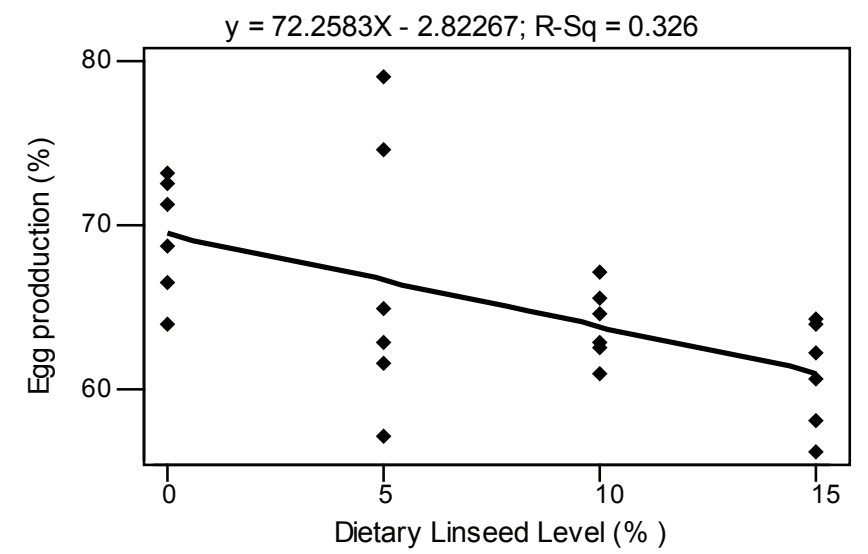

Figure 1 - Effect of dietary linseed on egg production of hens in hot climate. decrease in egg production when layers were fed 15\% linseed. On the other hand, Jiang et al. (1991), Caston et al. (1994), and Bean \& Leeson (2003) showed that feeding up to $10 \%$ linseed to the hens did not effect egg production. Scheideler \& Froning (1996) reported a decrease in feed intake when hens were fed linseed, as found in the present study.

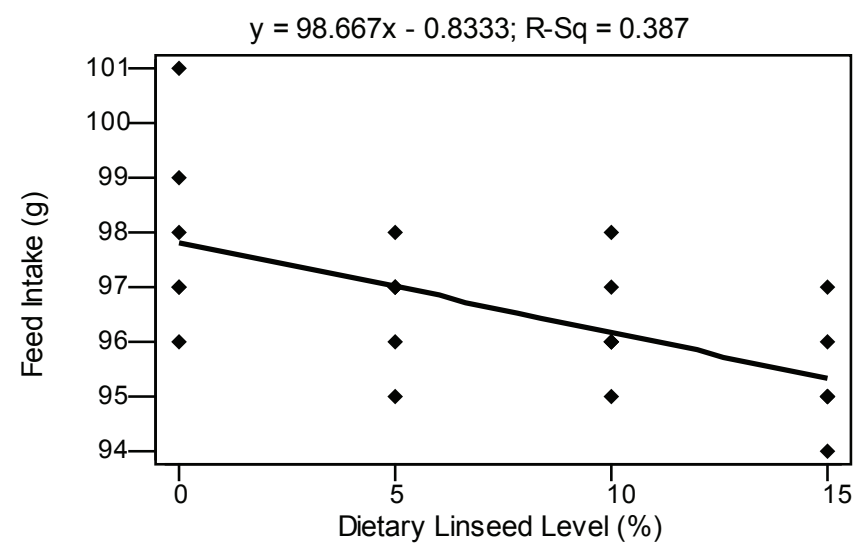

Figure 2 - Effect of Dietary linseed on feedintake of hens in hot climate.

All evaluated egg quality and eggshell quality parameters, such as egg weight, yolk weight, albumen height, eggshell thickness and eggshell weight, were not influenced by the increase in dietary linseed levels. These results are consistent with the findings of Scheideler et al. (1998), Novak \& Scheideler (2001), and Bean \& Leeson (2003), who reported no change in these egg characteristics in layers fed diets containing linseed. On the other hand, Baynen (2004), and Sosin et al. (2006) reported that feeding layers with linseed reduced ( $p \leq 0.05$ ) egg weight, while yolk weight remained constant. 
Based on the results of present study, it was concluded that feeding linseed to laying hens reared in hot climate had detrimental effects on egg production, feed intake and FCR, but no influence on egg or eggshell quality. Further studies are needed to evaluate the effect of linseed feeding on the production performance of laying hens.

\section{REFERENCES}

Aymond, WM, VanElswyk ME. Yolk thiobarbituric acid reactive substances and $n-3$ fatty acids in response to whole and ground flaxseed. Poultry Science 1995;74:1388-1394

Bean LD, Leeson S. Long-term effects of feeding flaxseed on performance and egg fatty acid composition of brown and white hens. Poultry Science 2003;82:388-394

Beynen AC. Fatty acid composition of eggs produced by hens fed diets containing groundnut, soybean or linseed. New Zealand Journal of Animal Science 2004; 52(1):3-10.

Botsoglou NA, Yannakopoulos LA, Fletouris DJ, Tserveni-Goussi AS, Psomas IE. Yolk fatty acid composition and cholesterol contents in response to level and form of dietary flaxseed. Journal of Agriculture and Food Chemistry 1998:46:4652-4656.

Caston LJ, Squires EJ, Leeson S. Hen performance, egg quality, and the sensory evaluation of eggs from SCWL hens fed dietary flax. Canadian Journal of Animal Science 1994;74:347-353.
Gonzalez-Esquerra R, Leeson S. Studies on the metabolizable energy content of full-fat flaxseed in mash, pellet, and crumbled diets assayed with birds of different ages. Poultry Science 2000;79:1603-1607.

Jiang Z, Ahn DU, Sim JS. Effects of feeding flax and two types of sunflower seeds on fatty acid composition of yolk lipid classes. Poultry Science $1991 ; 70: 2467-2475$

National Research Council. Nutrient requirements of Poultry. $9^{\text {th }}$ rev. ed National Academy Press, Washington DC; 1994.

Novak C, Scheideler SE. Long-term effects of feeding flaxseed-based diets. 1. egg Production parameters, components, and eggshell quality in two strains of laying hens. Poultry Science 2001;80:1480-1489.

Ortiz LT, Rebole A, Alzueta C, Rodrıguez ML, Trevino J. Metabolizable energy value and digestibility of fat and fatty acids in linseed determined with growing broiler chickens. British Poultry Science 2001;42:57-63.

Rodrıguez ML, Alzueta C, Rebole A, Ortiz LT, Centeno C, Trevino J. Effect of inclusion level of linseed on the nutrient utilization of diets for growing broiler chickens. British Poultry Science 2001;42:368-375.

Scheideler SE, Froning GW. The combined influence of dietary flaxseed variety, level, form, and storage conditions on egg production and composition among vitamin E-supplemented hens. Poultry Science 1996;75:1221-1226.

Sosin E, Borowiec F, Strzetelski J, Smulikowska S. The effect of feeding regular or low $\alpha$-linolenic acid linseed on the fatty acid composition of egg yolks. Journal of Animal Feed Science 2006;15:641-650.

Steel RGD, Torrie JH, Dickey JD. Principles and procedures of statistics: A biometrical approach. $3^{\text {rd }}$ ed. New york, McGraw-Hill Book; 1997. 